\title{
PENGARUH FAKTOR TEKNIS PENANGKAPAN TERHADAP PRODUKTIVITAS BAGAN PERAHU DI PERAIRAN KABUPATEN MAMUJU TENGAH, SULAWESI BARAT
}

\section{THE IMPACT OF CATCHING TECHNIQUE TO THE PRODUCTIVITY OF BOAT LIFT NET INI CENTRAL MAMUJU WATERS, WEST SULAWESI}

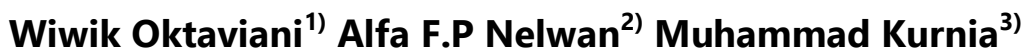 \\ ${ }^{1}$ Program Studi Pemanfaatan Sumberdaya Perikanan, Fakultas Ilmu Kelautan dan Perikanan, Universitas \\ Hasanuddin
}

Diterima: 05 Januari 2019; Disetujui: 14 Februari 2019

\begin{abstract}
ABSTRAK
Efektivitas suatu alat tangkap, ditentukan oleh faktor teknis penangkapan. Penelitian ini bertujuan untuk menentukan produktivitas bagan perahu, menganalisis faktor teknis penangkapan yang berpengaruh terhadap produktivitas penangkapan, dan mendeskripsikan komposisi hasil tangkapan. Penelitian ini dilakukan di Desa Tobinta, Kecematan Karossa, Kabupaten Mamuju Tengah dari bulan Juni sampai Agustus 2018. Metode penelitian yang digunakan adalah studi kasus, dengan menggunakan analisis spearman untuk mengetahui faktor teknis yang berpengaruh. Hasil penelitian ini menunjukkan produktivitas bagan perahu yang mengalami tren peningkatan dari hauling I ke hauling II. Faktor teknis memiliki kedekatan hubungan atau cukup berpengaruh terhadap produktivitas bagan perahu, dan proporsi jenis ikan hasil tangkapan bagan perahu yang terbesar adalah tembang (Sardinella fimbriata) dan proporsi terendah adalah tongkol (Euthynnus affinis).
\end{abstract}

Kata Kunci: Bagan perahu, Produktivitas, Teknis penangkapan.

\begin{abstract}
The effectiveness of fishing gear depends by technical factor of fishing activity. This research aimed to determine the productivity of the boat lift net, to analyze the technical factors of fishing that affect the productivity of the catches, and to describe the composition of the catches. This research was conducted in Tobinta Village, Karossa Subdistrict, Central Mamuju Regency from June to August in 2018. And i use a case study method using spearman analysis to determine the influential technical factors. The results of this study showed that boat lift net productivity in the Central Mamuju waters based on statistics changes from the first hauling to second hauling. The technical factor of catching a boat lift net that had a close relationship with the productivity of the catches was the length of the catch. Moreover, the fish resources in the boat lift net in Tobinta Village which were caught most were sardinella (Sardinella fimbrata) and the lowest was tuna fish (Euthynnus affinis).
\end{abstract}

Keywords: Boat lift net, Fishing productivity, Technical fishing.

\begin{tabular}{ll}
\hline Contact person & : Wiwik Oktaviani \\
E-Mail & $:$ wiwikoktaviani150@gmail.com
\end{tabular}




\section{PENDAHULUAN}

Bagan perahu termasuk dalam klasifikasi jaring angkat yang dioperasikan tidak jauh dari pesisir pantai. Dalam pengoperasiannya bagan menggunakan lampu sebagai teknologi alat bantu penangkapan ikan (Nelwan dkk, 2015). Secara umum konstruksi unit penangkapan bagan perahu terdiri dari kerangka kayu, waring/jaring. Informasi kemampuan tangkap sangat dibutuhkan untuk perencanaan pengembangan dan tindakan pengelolaan agar usaha kegiatan penangkapan dan ketersedian ikan di Mamuju Tengah sebagai wilayah baru dari hasil pemekaran dapat diketahui.

Produktivitas penangkapan merupakan kemampuan suatu alat tangkap untuk mendapatkan sejumlah hasil tangkapan dalam setiap satuan upaya. Upaya penangkapan merupakan sejumlah upaya yang diadakan untuk memperoleh hasil tangkapan yang maksimal. Upaya penangkapan berkaitan dengan faktor teknis penangkapan (Nelwan dkk, 2015).

Berdasarkan produktivitas yang dihasilkan suatu alat tangkap bagan perahu, terdapat beberapa faktor teknis penangkapan yang berpengaruh terhadap aktivitas penangkapan. Aspek teknis penangkapan pada setiap unit penangkapan itu berbeda, karena mekanisme pengoperasian dan tujuan penangkapan berbeda.

$$
\text { Aspek teknis penangkapan }
$$

didekskripsikan sebagai komponen yang berpengaruh terhadap terhadap keberhasilan suatu operasi penangkapan ikan. Kasus dalam skripsi ini adalah bagan perahu, pemilihan bagan perahu karena bagan perahu adalah salah satu alat tangkap yang banyak digunakan oleh pelaku usaha penangkapan ikan di Kabupaten Mamuju Tengah.

Aspek teknis akan berpengaruh terhadap efektivitas pengoperasian suatu alat tangkap. Dengan demikian, penting untuk diketahui aspek teknis yang demikian berpengaruh terhadap pengoperasian alat suatu alat tangkap. Ketepatan dalam menentukan aspek teknis yang berpengaruh akan bermanfaat untuk para pelaku usaha penangkapan ikan.

Oleh karena itu, penelitian mengenai "Pengaruh Faktor Teknis Penangkapan Terhadap Produktivitas Penangkapan Bagan Perahu di Perairan Kabupaten Mamuju Tengah" perlu dilakukan agar hasil penelitian bisa disosialisasikan dan menjadi informasi penting bagi nelayan untuk mengoptimalkan hasil tangkapan dan efisiensi dalam melakukan penangkapan ikan.

\section{METODE PENELITIAN Waktu dan Tempat}

Penelitian ini dilaksanakan di Kecamatan Karossa Kabupaten Mamuju Tengah, Sulawesi Barat, dari bulan Juni sampai Agustus 2018

\section{Metode Pengumpulan Data}

Data yang dikumpulkan adalah data primer dan data sekunder. Data primer diperoleh melalui observasi langsung dengan mengikuti operasi penangkapan pada satu unit bagan perahu di Kabupaten Mamuju sebanyak 30 trip penangkapan. Jenis data primer yang dikumpulkan yaitu:

1. Data hasil tangkapan di peroleh dengan cara menimbang berat $(\mathrm{kg})$ hasil tangkapan berdasarkan jenis ikan. Pencatatan data hasil tangkapan dilakukan pada setiap trip penangkapan berdasarkan waktu hauling. 
2. Data durasi waktu efektif penangkapan di peroleh dengan cara menghitung waktu (menit) dimulai dari penyalaan lampu sampai bingkai jaring muncul di permukaan. Pencatatan data ini dilakukan setiap kali hauling.

3. Mencatat posisi geografis lokasi penangkapan setiap kali trip.

4. Penentuan jarak fishing base ke fishing ground yakni mengkonversi menggunakan aplikasi ArcGis.

5. Melakukan wawancara dengan nelayan untuk melengkapi data yang diinginkan.

Data sekunder diperoleh dari studi literatur untuk sebagai penunjang penelitian untuk menunjukkan keabsahan suatu penelitian, dan mengetahui jenis ikan yang tertangkap dengan mencocokkan beberapa literatur digunakan antara lain (Allen, 1999), dan website http//:www.fishbase.org.

\section{Analisis Data}

\section{Menghitung Produktivitas Penangkapan}

Pada tahap ini dilakukan perhitungan produktivitas hasil tangkapan bagan perahu setiap kali hauling. Perhitungan produktivitas bagan perahu menggunakan persamaan sebagai berikut:

$$
\text { Produktivitas }=\frac{c}{t}
$$

Dimana,

$\mathrm{C}=$ jumlah hasil tangkapan $(\mathrm{kg})$

$\mathrm{t}=$ waktu efektif penangkapan ikan (menit), merupakan waktu efektif penangkapan dihitung mulaipenyalaan lampu sampai bingkai jaring bagan tampak di permukaan.

\section{Analisis Hubungan antara Produktivitas dengan Faktor Teknis Penangkapan}

a. Untuk mengetahui hubungan antara produktivitas dengan waktu hauling dan jarak fishing base ke fishing ground terlebih dahulu dilakukan uji normalitas sebaran data sebagai syarat untuk analisis statistik parametrik. Karena data tersebut tidak terdistribusi normal maka dilakukan transformasi data dengan cara dipangkatkan, dilogaritmakan, dan Ln. Setelah itu, dilakukan transformasi, ternyata data tersebut masih tidak terdistribusi normal sehingga dilakukan analisis regresi non-parametrik Spearman.

b. Analisis data juga dilakukan secara deskriptif menggunakan tLAable dan grafik. Salah satu grafik yang digunakan adalah histogram. Grafik histogram dibuat dengan menggunakan jumlah kelas yang ditentukan dengan menggunakan persamaan sturgess yang dikemukakan dalam penelitian Sturges (1962) dalam Bubun dan Amir (2015), sebagai berikut.

$$
K=1+3,3 \log N
$$

$$
\begin{aligned}
& \text { Dimana: } \\
& \mathrm{K}=\text { Jumlah kelas } \\
& \mathrm{N}=\text { Jumlah data }
\end{aligned}
$$

c. Selanjutnya dilakukan perhitungan selang kelas dengan menggunakan persamaan sebagai berikut.

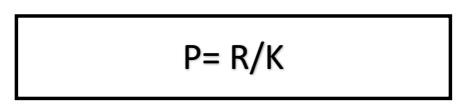

$$
\begin{aligned}
& \text { Dimana: } \\
& \mathrm{P}=\text { Selang kelas }
\end{aligned}
$$

$\mathrm{R}=$ Kisaran (jarak terjauh- jarak terdekat)

$\mathrm{K}=$ Jumlah kelas

d. Selanjutnya data produktivitas penangkapan dikelompokkan berdasarkan selang kelas. Semua data produktivitas yang berada di selang kelas tersebut dijumlahkan. 


\section{Menghitung komposisi jenis hasil tangkapan}

Pada tahap ini dilakukan perhitungan komposisi jenis hasil tangkapan bagan perahu pada setiap jenis ikan dimana komposisi tersebut dihitung berdasarkan waktu hauling. Perhitungan komposisi jenis hasil tangkapan menggunakan persamaan sebagai berikut:

$$
K J=\frac{n i}{N} \times 100 \%
$$

\section{Dimana:}

$\mathrm{ni}=$ jumlah hasil tangkapan spesies $\mathrm{ke} \mathrm{i}(\mathrm{kg})$ $\mathrm{N}=$ jumlah total hasil tangkapan bagan perahu $(\mathrm{kg})$

\section{HASIL DAN PEMBAHASAN}

\section{Produktivitas Penangkapan Bagan Perahu}

Produktivitas bagan perahu dalam satu trip penangkapan biasanya terdapat dua kali hauling. Produktivitas penangkapan bagan perahu merupakan besaran hasil tangkapan yang diperoleh dari jumlah hasil tangkapan per hauling dibagi dengan waktu efektif penangkapan, yang mana waktu efektif penangkapan dihitung mulai dari penyalaan lampu sampai rangka bagan tampak ke permukaan.

Deskripsi perubahan produktivitas penangkapan pada bagan perahu di perairan Mamuju Tengah secara statistik ditampilkan pada Tabel 2 .

Tabel 2. Deskripsi statistik produktivitas penangkapan bagan perahu di perairan Mamuju Tengah

\begin{tabular}{cccc}
\hline No & $\begin{array}{c}\text { Deskripsi } \\
\text { Statistik }\end{array}$ & Hauling 1 & $\begin{array}{c}\text { Hauling } \\
\mathbf{2}\end{array}$ \\
\hline $\mathbf{1}$ & Rata- rata & 0,19 & 0,56 \\
\hline $\mathbf{2}$ & Maksimun & 0,94 & 0,06 \\
\hline $\mathbf{3}$ & Minimun & 0,01 & 1,43 \\
\hline $\mathbf{4}$ & N (Jumlah data) & 30 & 11 \\
\hline
\end{tabular}

Produktivitas penangkapan selama 30 trip penangkapan masing-masing hauling 1 dan 2 sebagai berikut.

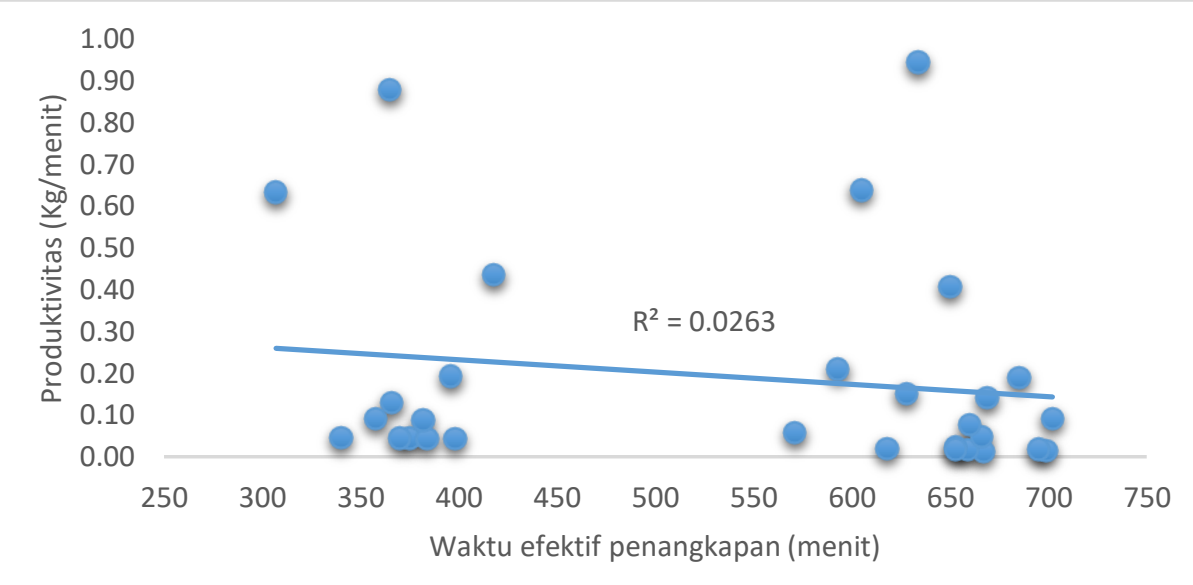

Gambar 1. Hubungan antara Produktivitas Penangkapan dengan waktu efektif penangkapa hauling I

Gambar 12 menunjukkan tren produktivitas penangkapan hauling I cenderung menurun. Produktivitas tertinggi berada pada $0,94 \mathrm{~kg} /$ menit, terjadi pada trip 4. Waktu yang dibutuhkan sekitar 634 menit dengan perolehan jumlah hasil tangkapan sebesar $597,375 \mathrm{~kg}$. Sedangkan produktivitas terendah berada pada $0,01 \mathrm{~kg} /$ menit, terjadi pada trip 10. Waktu yang dibutuhkan sekitar 667 menit dengan perolehan jumlah hasil tangkapan 6,99 
kg. Produktivitas penangkapan hauling I memiliki koofisien determinasi $\left(R^{2}\right)=0,0263$ ini menunjukkan bahwa pengaruh waktu efektif penangkapan terhadap produktivitas penangkapan sebesar 0,0263 \% sedangkan sisanya dipengaruhi oleh faktor lainnya. Total produktivitas penangkapan pada hauling I yakni sebesar $5,73 \mathrm{~kg} /$ menit.

Produktivitas penangkapan bagan perahu hauling II dapat dilihat pada Gambar 13.

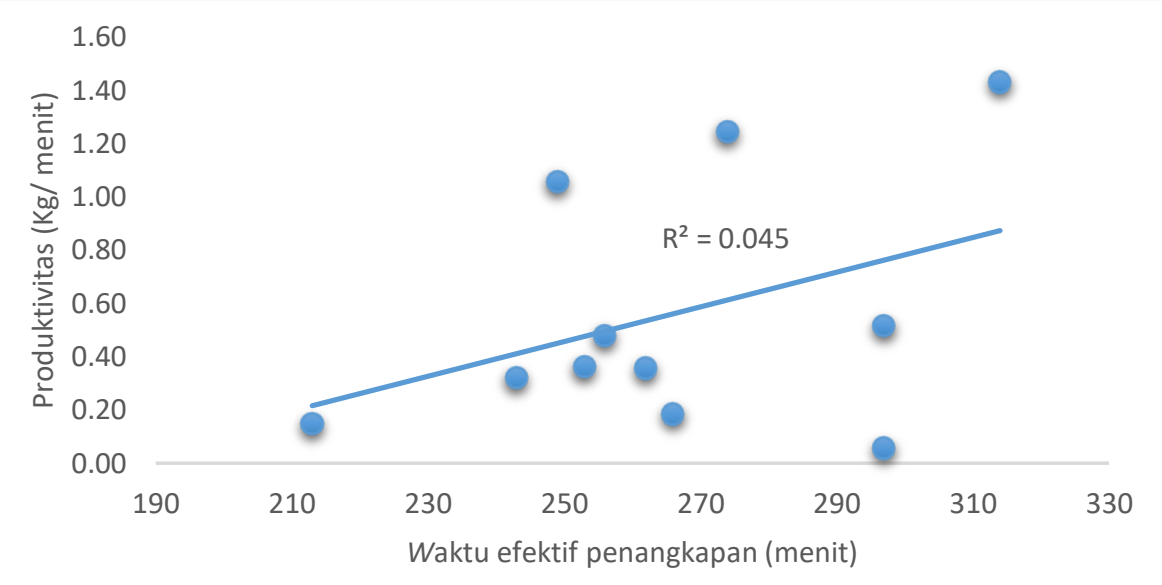

Gambar 2. Hubungan antara Produktivitas Penangkapan dengan waktu efektif penangkapan hauling II

Gambar 13 menunjukkan tren produktivitas penangkapan hauling II cenderung meningkat. Produktivitas tertinggi berada pada $1,43 \mathrm{~kg} /$ menit, terjadi pada trip 18. Waktu yang dibutuhkan sekitar 314 menit dengan perolehan jumlah hasil tangkapan sebesar 449,1 kg. Sedangkan produktivitas terendah berada pada $0,06 \mathrm{~kg} /$ menit, terjadi pada trip 6. Waktu yang dibutuhkan sekitar 297 menit dengan perolehan jumlah hasil tangkapan 16,997 kg. Produktivitas penangkapan hauling II memiliki koofisien determinasi $\left(R^{2}\right)=0,045$ ini menunjukkan bahwa pengaruh waktu efektif penangkapan terhadap produktivitas penangkapan sebesar $0,045 \%$ sedangkan sisanya dipengaruhi oleh faktor lainnya. Total produktivitas penangkapan pada hauling II yakni sebesar $6,16 \mathrm{~kg} /$ menit.

Berdasarkan produktivitas penangkapan berdasarkan waktu hauling menunjukkan tren produktivitas berbeda pada hauling I dan II. Tren produktivitas menunjukkan indikator ketersediaan ikan di suatu daerah penangkapan Nelwan dkk, (2015). Fluktuasi jumlah hasil tangkapan bagan perahu berdasarkan waktu penarikan jaring (hauling) cenderung meningkat, dimana dalam satu trip penangkapan umumnya terdapat dua kali penarikan jaring. Perbedaan jumlah hasil tangkapan dalam setiap satuan waktu penarikan jaring disebekan oleh berbagai faktor, namun dapat diduga perbedaan jumlah hasil tangkapan berkaitan dengan pola dan kebiasaan makan kelompok jenis ikan pelagis Freon dkk, (2005) dalam Nelwan dkk, (2015), selain itu perbedaan jumlah hasil tangkapan berkaitan dengan respon terhadap cahaya berasal dari bagan perahu yang menggunakan lampu sebagai teknologi alat bantu (Sudirman dan Baskoro, 2012). Namun pada penelitian ini tidak melakukan pengukuran intensitas cahaya, dengan demikian penting dilakukan untuk penelitian selanjutnya. Berdasarkan hasil wawancara dan pengamatan secara langsung 
pengaruh arus memang cukup berpengaruh. Perbedaan produktivitas penangkapan hauling I dan hauling II juga diduga dipengaruh oleh kecepatan arus walaupun tidak dilakukan pengambilan data kecepatan arus. Perbedaan kecepatan arus itu menyebabkan respon ikan terhadap cahaya berbeda sehinggah ketika kecepatan arus hauling II lebih rendah dibanding hauling I menyebabkan pencahayaan lampu diduga lebih terfokus sehingga penetrasi kedalam cahaya itu lebih besar dibanding hauling I. Hal ini sejalan yang dikemukan oleh Kurnia dkk, (2015) yang mengemukakan bahwa arus yang terlalu kencang juga akan membuat distribusi cahaya yang masuk ke perairan menjadi terpecah sehinggah membuat ikan menjadi tidak terfokus dan menyebar sedangkan ikan yang tertarik pada cahaya menyukai cahaya yang terang dan tenang.

\section{Pengaruh Faktor Teknis Penangkapan Terhadap Produktivitas Penangkapan}

Untuk mengetahui hubungan antara produktivitas dengan waktu efektif penangkapan dan jarak, data yang diperoleh harus dinormalkan terlebih dahulu menggunakan uji normalitas untuk mengetahui apakah data tersebut terdistribusi normal. Setelah dilakukan uji normalitas didapatkan nilai signifikan lebih kecil dari level kepercayaan yakni $<0.05$ yang berarti $\mathrm{H}_{\circ}$ ditolak dan data tidak terdistribusi normal. Oleh sebab itu dilakukan transformasi data kedalam bentuk lain. Ada banyak cara mentransformasikan data, tetapi cara yang sering digunakan yakni dalam bentuk kuadrat, Log, dan Ln. Setelah dilakukan transformasi data dengan cara tersebut, ternyata $\mathrm{H}_{\circ}$ masih tetap ditolak yang artinya data masih tetap tidak terdistribusi normal. Berdasarkan hal tersebut maka data diolah menggunakan statistik non parametrik spearman.

Hubungan antara produktivitas penangkapan dan jarak dan waktu efektif penangkapan dapat dilihat pada Tabel 3.

Tabel 3. Hasil analisis korelasi spearman antara jarak dan waktu dengan produktivitas bagan perahu

\begin{tabular}{ccc}
\hline & & Nilai Korelasi \\
\hline & Sig. & $\begin{array}{c}\text { Produktivitas } \\
\text { penangkapan }\end{array}$ \\
\hline $\begin{array}{c}\text { Jarak } \\
\text { Waktu efektif } \\
\text { penangkapan }\end{array}$ & 0,738 & 0,054 \\
\hline
\end{tabular}

Berdasarkan hasil uji statistik non parametrik spearman menunjukkan bahwa nilai signifikan antara produktivitas dengan jarak penangkapan sebesar 0,738, dimana nilai tersebut lebih besar dari 0,05 maka dapat disimpulkan bahwa tidak terdapat korelasi yang signifikan antara variabel yang dihubungkan. Sedangkan koefisien korelasi antara produktivitas dan jarak penangkapan sebesar 0,054, nilai tersebut menandakan hubungan korelasi yang rendah antara produktivitas dengan jarak penangkapan. Hal ini menunjukkan bahwa tidak terdapat perbedaan yang signifikan antara daerah penangkapan ikan bagan perahu yang terletak jauh dan dekat dari pantai.

Setelah dilakukan pengambilan data sebanyak 30 kali diperoleh jarak rata-rata penangkapan yakni 4,4923 km. Tetapi meskipun begitu, produktivitas penangkapan cenderung rendah hal ini sesuai diperkuat berdasarkan hasil wawancara dengan nelayan 
yang menyatakan bahwa keuntungan usaha cenderung menurun.

Hal tersebut sesuai dengan penelitian Susaniati dkk, (2013) menunjukkan bahwa tidak terdapat perbedaan yang signifikan antara produktivitas penangkapan bagan tancap yang dioperasikan jauh dan dekat dengan pantai. Hal tersebut menunjukkan bahwa keadaan perikanan di luasan daerah penangkapan bagan tancap cenderung sama. Besaran produktivitas penangkapan di perairan pantai kabupaten Jeneponto rendah atau tinggi belum ada rujukan, namun berdasarkan wawancara dengan nelayan bahwa selama ini keuntungan usaha cenderung menurun atau mengalami kerugian.

Berdasarkan hasil uji statistik non parametrik spearman menunjukkan bahwa nilai signifikan antara produktivitas dengan waktu efektif penangkapan diperoleh nilai sig. sebesar 0,189, dimana nilai tersebut mengindikasikan rendahnya hubungan (korelasi) antara produktivitas dan waktu efektif penangkapan. Sedangkan koofisien korelasi antara produktivitas dan waktu efektif penangkapan sebesar 0,209, nilai tersebut menandakan hubungan korelasi yang rendah antara produktivitas dengan waktu efektif penangkapan.

Hal tersebut sesuai dengan penelitian yang dilakukan oleh (Zulfiah, 1999) menyatakan ada beberapa jenis ikan yang tidak berpengaruh terhadap waktu hauling seperti ikan teri, selar, kembung, dan alu-alu. Peluang tertangkapnya ikan teri sebelum dan sesudah tengah malam adalah sama. Ikan teri tidak menunjukkan sifat lebih aktif pada waktu-waktu tertentu.

Fluktuasi produktivitas penangkapan berdasarkan jarak penangkapan sebagaimana dilihat pada Gambar 15.

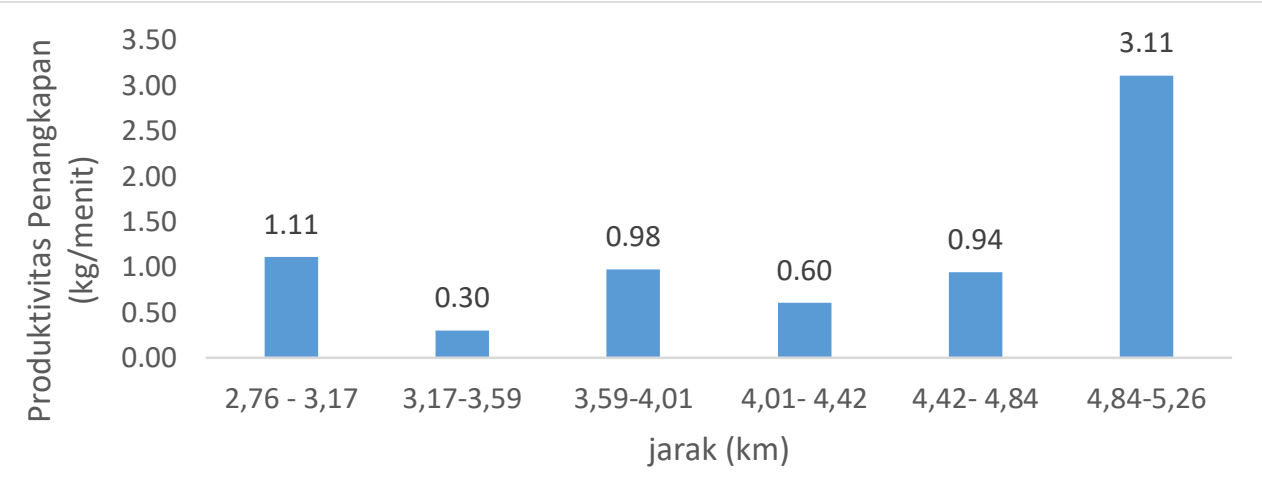

Gambar 3. Fluktuasi produktivitas penangkapan berdasarkan jarak penangkapan

Gambar 15 menunjukkan fluktuasi produktivitas penangkapan dengan jarak penangkapan. Produktivitas tertinggi berada pada interval jarak 4,84- 5,26 km dengan total produktivitas mencapai $3,11 \mathrm{~kg} /$ menit. Sedangkan terendah berada pada interval jarak 3,17-3,59 km dengan total produktivitas sebanyak 0,30 kg/menit. Berdasarkan diagram di atas dapat disimpulkan bahwa kisaran jarak fishing ground bagan perahu yaitu 2,76 - 5,26 km. Adapun total tangkapan optimum diperoleh pada interval jarak 4,84- 5,26 km. Tingginya tangkapan pada interval jarak yang jauh diduga karena jarak yang dekat tingkat pencemaran cukup tinggi sehinggah ikan bergerak ke perairan yang sedikit lebih jauh. Selain itu, pencemaran juga diduga dapat meningkatkan kekeruhan perairan pada kawasan yang dekat dengan pesisir akibatnya peran lampu sebagai pemikat (atraktor) ikan di 
perairan menjadi tidak optimal. Hal tersebut sesuai yang dikemukan oleh Sihombing (2014) dalam Apriliani dkk, (2018) juga menyatakan kondisi air yang kurang baik membuat hasil tangkapan lebih sedikit.
Hubungan jarak penangkapan dengan jenis ikan hasil tangkapan sebagaimana dilihat pada Gambar 16.

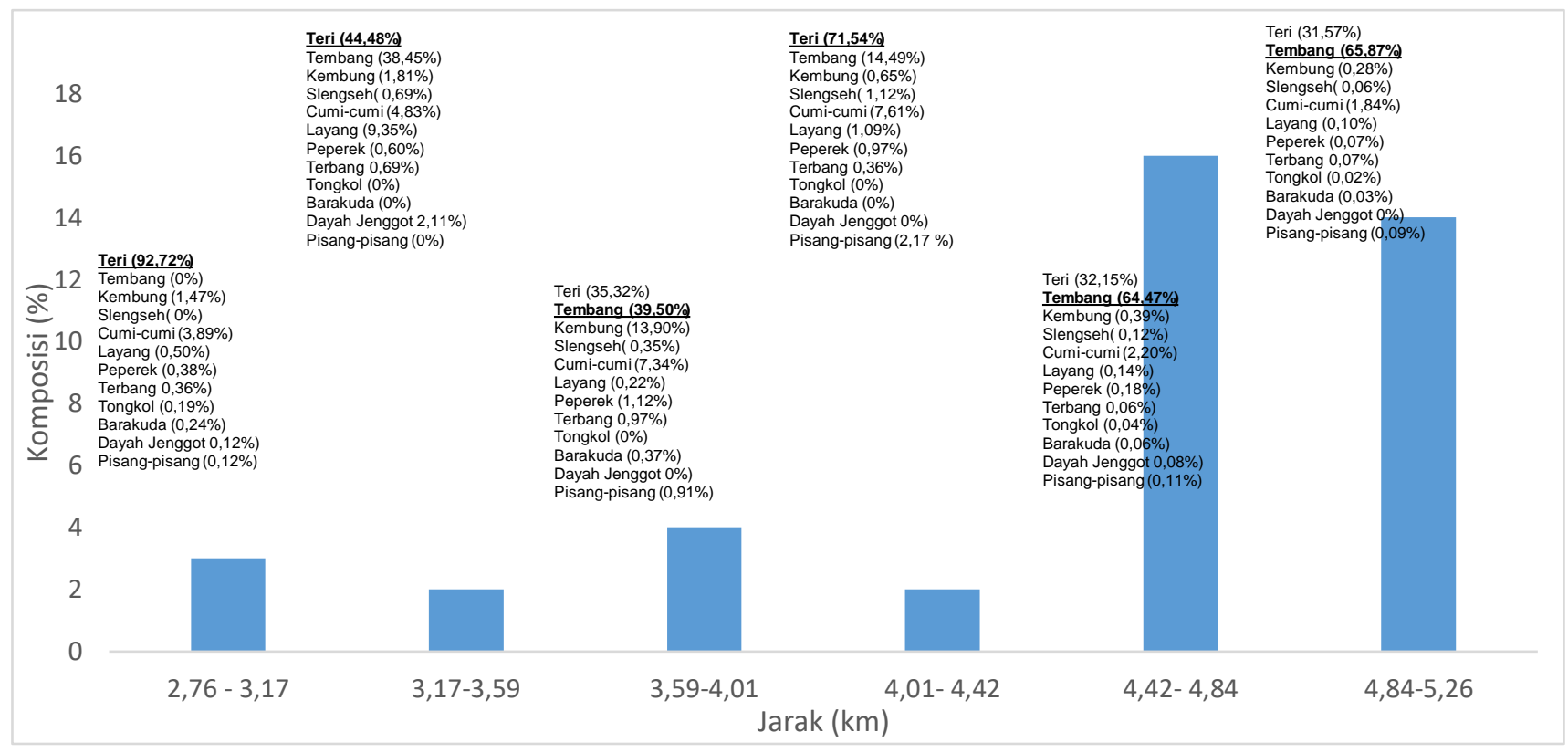

Gambar 4. Diagram perubahan proporsi jenis ikan hasil tangkapan

Pada Gambar 16 menunjukkan perubahan proporsi ikan yang tertangkap pada jarak tertentu. Pada interval jarak terendah 2,76-3,17 km, ikan dominan yang tertangkap yakni ikan teri dan pada interval jarak tertinggi 4,84-5,26 km yakni tembang. Tetapi, pada interval jarak terendah terdapat 10 jenis ikan yang berada pada interval jarak tersebut sedangkan, pada interval jarak tertinggi terdapat 11 spesies yang tertangkap. Perbedaan jumlah spesies yang tertangkap diduga karena di daerah penangkapan tersebut terdapat muara yang dapat mempengaruhi lingkungan daerah penangkapan.

Hal tersebut juga diduga karena perairan pesisir cenderung tidak stabil mengingat adanya pengaruh dari daratan yang lebih besar. Hal ini menyebabkan sifat fisik-kimiawi perairan cenderung fluktuatif. Perairan pesisir merupakan bagian batas terluar yang masih dipengaruhi oleh prosesproses alami yang terjadi di darat, hal ini memberikan pengertian bahwa perairan pesisir merupakan ekosistem dinamis dan memiliki kekayaan yang beragam (Suprapto dkk, 2014). Banyaknya jumlah hasil tangkapan juga dipengaruhi oleh ketersediaan makanan di suatu perairan. Ketersediaan makanan merupakan salah satu faktor yang menentukan kelimpahan populasi serta kondisi ikan di suatu perairan (Rizwan dkk, 2014 dalam Apriliani dkk, 2018).

Persentase ikan yang tertangkap dominan yakni tembang dan teri. Distribusi tangkapan ikan dari jarak jauh dan dekat dengan pantai didominasi ikan teri dan tembang hal ini diduga karena makanan 
utama ikan tembang dan teri yakni fitoplankton dan zooplankton (Allen, 1997 dalam Apriliani dkk, 2018). Kelimpahan zooplankton pada saat pasang (dini hari) lebih tinggi dibandingkan saat surut (pagi hari), hal ini terkait dengan pola migrasi harian vertikal harian zooplankton. Zooplankton akan naik ke permukaan pada malam hari atau dini hari (Nontji, 2007 dalam Apriliani dkk, 2018). Hal tersebut yang menybabkan ikan tembang dan teri akan cenderung berkorelasi positif dengan kelimpahan fitoplankton dan zooplankton, daerah cenderung tidak jauh dari pantai merupakan tempat yang cocok, selain pengaruh pasang surut juga adanya run off dari darat akan menambah jumlah nutrient dan membawa banyak fitoplankton yang berkumpul.

\section{Komposisi Jenis Hasil Tangkapan}

Komposisi jenis hasil tangkapan merupakan indikasi keberadaan jenis ikan pada suatu wilayah perairan yang merupakan daerah penangkapan ikan. Komposisi jenis hasil tangkapan hauling I pada bagan perahu selama pengambilan data menunjukkan kecenderungan didominasi oleh ikan teri dan tembang, sebagaimana dilihat pada Gambar 17.

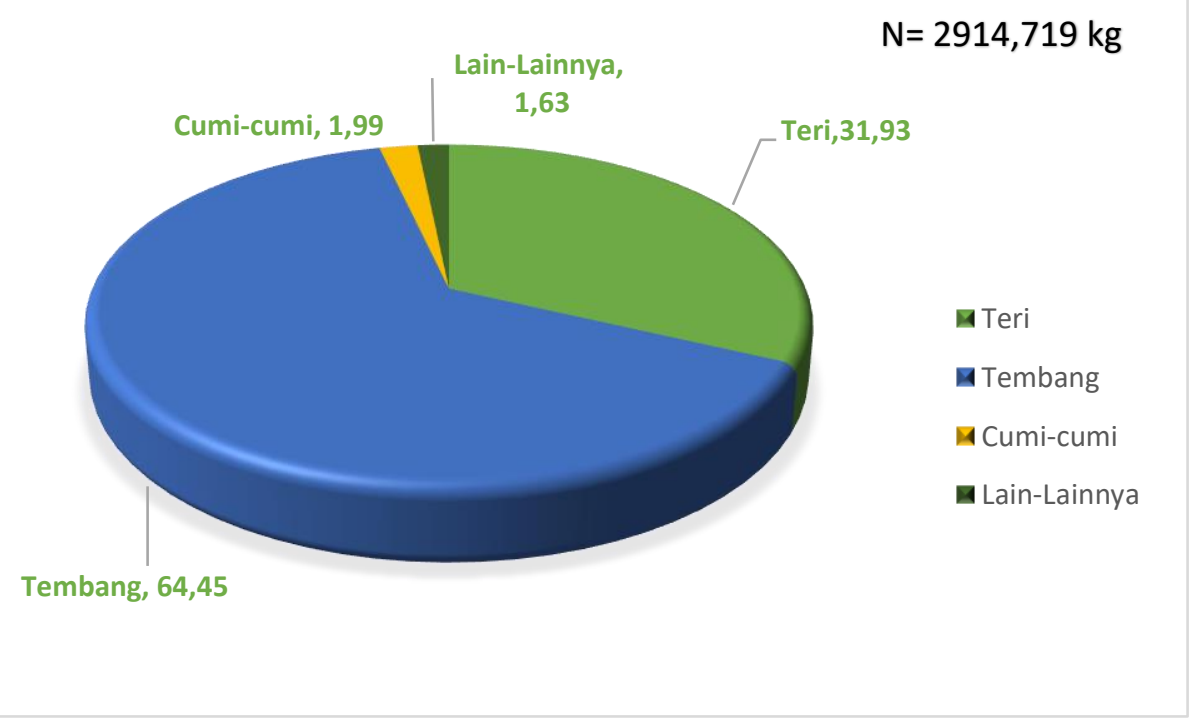

Gambar 5. Komposisi jenis hasil tangkapan dominan bagan perahu hauling I

Gambar 17 menunjukkan fluktuasi hasil tangkapan bagan perahu hauling I selama 30 trip penangkapan. Jenis ikan yang tertangkap pada hauling I selama 30 trip penangkapan yakni teri (Stolephorus sp), tembang (Sardinella fimbriata), Barakuda (Sphyraena barracuda), cumi-cumi (Loligo sp), peperek (Leiognatus sp), kembung perempuan (Rastrelliger brachysoma), pisang-pisang (Pterocaesio chryzona), kembung lelaki (Rastrelliger kanagurta), tongkol (Euthynnus affinis), ikan terbang (Hirundichthys sp), layang (Decapterus sp), dan dayah jenggot (Parupeneus barberinus). Jumlah total hasil tangkapan hauling I sebanyak 2914,179 kg. Hasil tangkapan terbanyak adalah ikan teri dan tembang, dimana ikan teri mendapatkan hasil tangkapan sebanyak 930,5 kg, kemudian disusul ikan tembang sebanyak 1878,05 kg, cumi-cumi $58,05 \mathrm{~kg}$, dan lain-lainnya yang terdiri dari : ikan kembung perempuan 20,68 
kg, ikan kembung lelaki 3,69 kg, ikan peperek $5.583 \mathrm{~kg}$, ikan terbang 2,62 kg, ikan tongkol 0,718 kg, ikan barakuda 2,49 kg, ikan dayah jenggot 0,9 kg, dan ikan pisang-pisang 5,43 kg. Menurut Sani dkk, (2016), ikan yang menjadi target tangkapan bagan adalah jenis ikan pelagis kecil yang memiliki sifat fototaksis positif atau jenis ikan yang tertarik terhadap cahaya. Kecendrungan ini disebabkan daya tembus cahaya pada pengoperasian hanya berada di permukaan.
Namun pada kenyataannya jenis-jenis ikan lain seperti predator dan non-fototaksis positif ikut tertangkap oleh bagan.

Komposisi jenis hasil tangkapan hauling II pada bagan perahu selama pengambilan data menunjukkan kecenderungan didominasi oleh ikan teri sebanyak $601,75 \mathrm{~kg}$ dan tembang sebanyak $1035,5 \mathrm{~kg}$, sebagaimana dilihat pada Gambar 18.

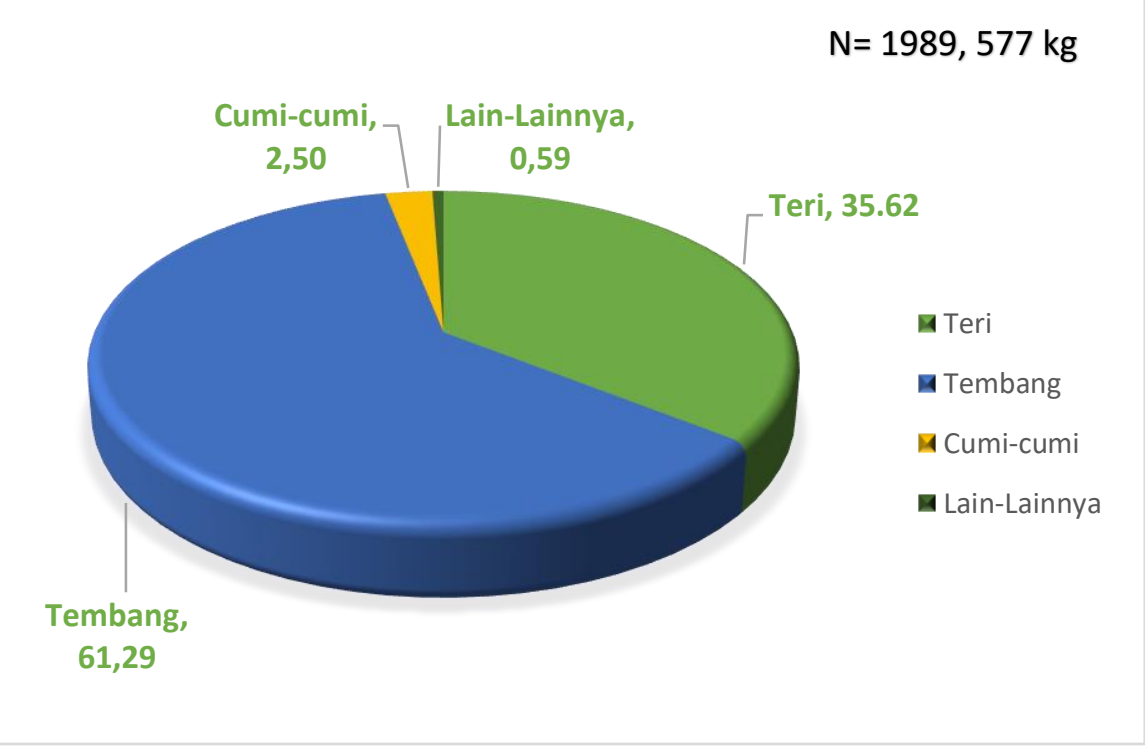

Gambar 6. Komposisi jenis hasil tangkapan dominan bagan perahu hauling II

Gambar 18 menunjukkan fluktuasi hasil tangkapan bagan perahu hauling II selama 30 trip penangkapan. Jenis ikan yang tertangkap pada hauling II selama 30 trip penangkapan yakni teri (Stolephorus sp), tembang (Sardinella fimbriata), Barakuda (Sphyraena barracuda), cumi-cumi (Loligo sp), peperek (Leiognatus sp), kembung perempuan (Rastreliger brachysoma), pisangpisang (Pterocaesio chryzona), kembung lelaki (Rastrelliger kanagurta), tongkol (Euthynnus affinis), ikan terbang (Hirundichthys s), layang ((Decapterus sp), dan dayah jenggot (Parupeneus barberinus). Jumlah total hasil tangkapan hauling II sebanyak 1689,577 kg. hasil tangkapan terbanyak adalah ikan teri dan tembang. Dimana ikan teri mendapatkan hasil tangkapan sebanyak 601,75 kg, kemudian disusul ikan tembang sebanyak 1035,5 kg, cumi-cumi $42,4 \mathrm{~kg}$ sedangkan lain-lainnya terdiri dari: ikan kembung perempuan $3,33 \mathrm{~kg}$, ikan kembung lelaki 0,93 kg, ikan peperek $1,057 \mathrm{~kg}$, ikan terbang $1,17 \mathrm{~kg}$, ikan tongkol $0,5 \mathrm{~kg}$, ikan barakuda 0,6 kg, ikan dayah jenggot 0,7 kg, dan ikan pisang-pisang 0,75 $\mathrm{kg}$.

Sumberdaya ikan tembang di perairan Tobinta melimpah hal ini diduga karena adanya mangrove yang menjadi tempat 
berkembang biaknya juvenile ikan tersebut. Proporsi ikan tembang lebih banyak di bandingkan ikan-ikan lainnya hal tersebut juga sesuai dengan penelitian Sani dkk, (2016) yang mengemukakan bahwa dari semua titik stasiun didapatkan jumlah hasil tangkapan sebanyak 5897,4 kg. Hasil tangkaapn ikan yang terbanyak adalah ikan selar dan ikan tembang. Dimana ikan tembang mendapatkan hasil tangkapan sebanyak 2364,9, kemudian disusul dengan ikan selar sebanyak 2005,6 kg sedangkan Alu-alu 515,4 kg, ikan petek 210,9 kg ikan cumi-cumi $60 \mathrm{~kg}$ dan ikan kembung 740,6 kg.

Menurut Lee, J.W (2010) meskipun bagan dikhususkan untuk menangkapan ikan pelagis kecil, namun pada kenyataannya ikan damersal seperti ikan belanak, ikan peperek, layur, bawal putih, cumi-cumi, dan gulamah ikut tertangkap. Tertangkapnya ikan demersal oleh bagan dapat disebabkan oleh tingkah laku ikan dalam mencari makan (feeding habit). Berkumpulnya ikan-ikan pelagis seperti teri dan tembang disekitar bagan akan memicu berkumpulnya ikan-ikan lain dengan ukuran lebih besar. Hal ini terjadi karena adanya siklus makan-memakan (rantai makanan) antara ikan kecil dengan predator yang berukuran lebih besar untuk mendapatkan makanannya. Oleh karena itu, kemunculan ikan teri kemudian diikuti dengan ikan-ikan predator baik dari jenis ikan damersal maupun ikan pelagis lainnya.

\section{KESIMPULAN}

Berdasarkan hasil penelitian dapat disimpulkan bahwa:

1. Produktivitas penangkapan bagan perahu yang dioperasikan di perairan Mamuju
Tengah, berdasarkan statistik mengalami perubahan dari hauling 1 ke hauling 2 .

2. Faktor teknis penangkapan bagan perahu yang memiliki kedekatan hubungan dengan produktivitas penangkapan adalah waktu efektif penangkapan.

3. Proporsi jumlah hasil tangkapan bagan perahu yang terbesar adalah Tembang (Sardinella fimbriata) dan proporsi terendah adalah tongkol (Euthynnus affinis).

\section{DAFTAR PUSTAKA}

Allen, G. 1999. Marine Fishes of South- East Asia. Australia: Periplus Edition (HK). Ltd.

Apriliani, I.M., I. Riyanti, E. Rochima, dan M.F.Ikmal. 2018. Laju Tangkapan Bagan Apung pada Jarak Penepatan Berbeda di Perairan Teluk Palabuhan ratu, Sukabumi, Indonesia. Jurnal Perikanan dan Kelautan. 8(1): 88-95.

Bahri, F. 2008. Perikanan Bagan Perahu dan Pengembangannya di Teluk Bima. [Skripsi]. Fakultas Perikanan dan Ilmu Kelautan, Intitut Pertanian Bogor.

Fauziah.S, F.K. Saleh, dan Hadi. 2013. Perbedaan Waktu Hauling Bagan Tancap terhadap Hasil Tangkapan di Perairan Sungsang, Sumatera Selatan. Jurnal Lahan Suboptimal. 2(1): 50-57.

Iskandar, M.D. 2001. Analisis Hasil Tangkapan Bagan Motor pada Tingkat Pencahayaan yang Berbeda di Perairan Teluk Semangka Kabupaten Tanggamus. [Tesis]. Bogor: Fakultas Perikanan dan Ilmu Kelautan. Institut Pertanian Bogor. 
Kurnia, M., Sudirman, dan A.F.P.Nelwan. 2015. Studi Pola Kedatangan Ikan pada Area Penangkapan Bagan Perahu dengan Teknologi Hidroakustik. Jurnal Ipteks PSP. 2(3): 261-271.

Nelwan, A.F.P., M.Nursam, dan M.N.Ihsan. 2015. Analisis Produktivitas Bagan Perahu di Perairan Kabupaten Polewali Mandar. Jurnal Ipteks PSP. 2(4). 345-356.

Nelwan, A.F.P., Sudirman, M.Nursam, dan M.A.Yunus. 2015. Produktivitas Penangkapan Ikan Pelagis di Peraiaran Kabupaten Sinjai Pada Musim Peralihan Barat-Timur. Jurnal Perikanan. 12 (1):18-26.

Nelwan, A.F.P., Sudirman, M.Zainuddin, dan M.Kurnia. 2015. Produktivitas Ikan Pelagis Besar Menggunakan Pancing Ulur yang Berpangkalan di Kabupaten Majene. Marine Fisheries. 2 (6): $129-142$.

Sani., A. Rosadi, Pramonowibowo, dan M. Triarso. 2016. Analisis Sebaran Daerah Penangkapan Ikan Pelagis Kecil dengan Alat Tangkap Bagan Perahu di Perairan Kabupaten Belitung. Journal of Fisheries Resources Utilization Management and Technology. 5(4): 71-79.

Sudirman dan A.Mallawa. 2012. Teknik Penangkapan Ikan. Jakarta: Rineka Cipta.

Sudirman dan M.S.Baskoro. 2004. "Respon Retina Mata Ikan Teri (Stolephorus Insularis) Terhdapa Cahaya Dalam Proses Penangkapan Pada Bagan Rambo." Jurnal Torani Unhas. 3(14): 18.

Suprapto, D., P.W. Purnomo, B. Sulardiono. 2014. Analisis Kesuburan Perairan Berdasarkan Hubungan Fisika
Kimia Sedimen Dasar dengan $\mathrm{NO}_{3}-$ $\mathrm{N}$ dan $\mathrm{PO}_{4}-\mathrm{P}$ di Muara Sungai Tuntang Demak. Jurnal saintek perikanan. 10(1):56-61.

Susianiati, Wardah, A.F.P.Nelwan dan M.Kurnia. 2013. Produktivtas Daerah Pengakapan Ikan Bagan Tancap yang Berbeda Jarak dari Pantai di Perairan Kabupaten Jeneponto. Jurnal Akuatik. 4(1): 68-79.

Zulfiah. 1999. Pengaruh Perbedaan Waktu Hauling terhadap Hasil Tangkapan Bagan Diesel di Perairan Carocok, Kabupaten Pesisir Selatan, Provinsi Sumatera Barat. [Skripsi]. Program Studi Pemanfaatan Sumberdaya Perikanan, Intitui Pertanian Bogor.

Lee, J.W. 2010. Pengaruh Periode Hari Bulan terhadap Hasil Tangkapan dan Tingkat Pendapatan Nelayan Bagan Tancap di Kabupaten Serang. [Tesis]. Sekolah Pascasarjana, Institut Pertanian Bogor. 